\title{
КОРРЕЛЯЦИОННЫЕ СВЯЗИ МНОГОЛЕТНИХ КОЛЕБАНИЙ МЕСЯЧНОГО И ГОДОВОГО СТОКА В БАССЕЙНЕ РЕКИ УРАЛ
}

\author{
(С) 2020 г. Д. Ю. Васильев ${ }^{a, b}, *$, В. В. Водопьянов ${ }^{a}$, Ш. И. Закирзянов ${ }^{a}$, А. Ж. Кенжебаева ${ }^{c}$, \\ В. А. Семенов ${ }^{b, d}$, Ж. Т. Сивохип ${ }^{e}$ \\ ${ }^{a}$ Уфимский государственный авиационный технический университет, Уфа, Россия \\ ${ }^{b}$ Институт физики атмосферы им. А.М. Обухова РАН, Москва, Россия \\ ${ }^{c}$ Московский государственный университет имени М.В. Ломоносова, Москва, Россия \\ ${ }^{d}$ Институт географии РАН, Москва, Россия \\ ${ }^{e}$ Институт степи УрО РАН, Оренбург, Россия \\ *e-mail: vasilevdy@ugatu.su \\ Поступила в редакцию 07.07.2019 г. \\ После доработки 13.10.2019 г. \\ Принята к публикации 30.01.2020 г.
}

\begin{abstract}
Статья посвящена изучению тесноты связей многолетних колебаний месячного и годового стока в бассейне р. Урал. Для рек этого бассейна вычислены нормы месячного и годового стока, с помощью метода вейвлет-анализа выявлены тенденции их изменения и циклы водности. Произведена оценка пространственной корреляции речного стока в пределах исследуемого речного бассейна. На основе модели периодически коррелированного процесса произведено прогнозирование временны́х рядов по выделенным гидрологическим сезонам, оценена теснота связей между среднемесячными расходами каждого месяца и среднегодовым расходом воды, а также между средними месячными расходами воды. Определена статистическая значимость выявленных корреляционных зависимостей. Установлена существенно более сильная коррелированность значений стока внутри года по сравнению с межгодовой, что может быть обусловлено наличием во временно́й структуре процесса долгопериодного колебания, на фоне которого проявляется ритмика годовой и внутригодовой цикличности. Предложено рассматривать колебания стока в бассейне р. Урал как случайный стохастический процесс, состоящий из двух компонент - инерционной (трендовая) и сезонной (осциллирующая).
\end{abstract}

Ключевые слова: расход воды, слой стока, р. Урал, корреляционные связи, вейвлет-анализ, Южный Урал DOI: $10.31857 / \mathrm{S} 2587556620030103$

\section{ВВЕДЕНИЕ}

В распределении стока рек внутри года основную роль играют климатические факторы, к которым относятся: общая увлажненность бассейна; особенность выпадения атмосферных осадков в разные сезоны, включая их интенсивность и продолжительность; температура воздуха; испаряемость; влажность воздуха [16]. Пространственновременны́е изменения климатических характеристик подчиняются определенным закономерностям, которые должны отражаться и в водном режиме рек. Оценке такого влияния, климатических факторов на сток рек, посвящено множество работ $[1,5,18-25]$, в том числе по бассейну р. Урал [7-15]. Существенное влияние на внутригодовое распределение стока может оказывать также антропогенная деятельность, прежде всего мероприятия по искусственному регулированию стока, главным образом сооружение водохранилищ $[2,3]$.
В соответствии с данными инструментальных наблюдений на метеорологических станциях по планете в целом с 1970-х годов наблюдается четкий положительный тренд в динамике приповерхностной температуры воздуха [36], причина которого остается до конца неопределенной. Представляет большой научный интерес выявление реакции водных ресурсов и динамики водного режима рек на это установленное потепление климата Земли. Следует отметить, что для территории Южного Урала, к которой относится и бассейн р. Урал, также характерен рост температуры воздуха, начиная с 1970-х годов [8, 9]. Основной целью данного исследования являлось изучение внутригодового распределения и прогнозирование стока р. Урал на основе модели периодически коррелируемого процесса. 


\section{ГИДРОГРАФИЯ БАССЕЙНА И МЕТОДИКА ОБРАБОТКИ ДАННЫХ}

Река Урал является составной частью бассейна Каспийского моря, исток реки находится на склонах вершины Круглая - сопка хр. Уралтау Южного Урала, устье расположено на западе Казахстана, где река впадает в Каспийское море, образуя два рукава - Яицкий и Золотой. Длина реки составляет 2428 км, по протяженности она третья в Европе. Площадь водосборного бассейна $231000 \mathrm{KM}^{2}$, максимальный расход воды - $400 \mathrm{M}^{3} \mathrm{c}^{-1}$, коэффициент извилистости составляет 2.38, а общее падение реки от истока к устью 788 м с уклоном $0.32 \%$. Урал имеет 82 притока, из которых 38 левые и 44 правые. В физико-географическом отношении бассейн р. Урал неоднороден, его северная часть расположена в горно-складчатой зоне Южного Урала. По долине р. Большой Ик и верховьям рр. Илек и Киялыбурти проходит граница между Уральскими горами и Русской равниной, в пределах которой находится вся средняя и нижняя часть бассейна. При движении с севера на юг четыре природные зоны сменяют друг друга: на правобережье р. Сакмары и в верховьях р. Урал развиты горно-лесостепные ландшафты, центральную часть бассейна занимает степная зона, южнее в устье р. Илек, степь сменяется полупустыней, а в низовьях р. Уил начинается пустынная зона [31]. Для большей части бассейна характерно снеговое питание, которое составляет $80 \%$, тогда как дождевое незначительно. Доля весеннего стока уменьшается по направлению с юга на север: в верховьях Урала оно составляет 58\%, а ниже по течению возрастает до 65\%. На рр. Миндяк, Большой и Малый Кизил, Карагайлы, Большой Ик, Зилаир и Сакмара доля стока за апрельмай составляет 60-70\% годового.

В качестве исходной информации для оценки тесноты связи многолетних колебаний стока в пределах бассейна р. Урал были взяты среднемесячные значения расхода воды по 14 гидрологическим постам (ГП), основные сведения по которым приведены в табл. 1. При выборе створов для оценки тенденций месячного и годового стока рек использовались ряды, продолжительность которых составляла более 50 лет и они характеризовались отсутствием или малым количеством пропусков в инструментальных наблюдениях. Известно, что сток реки можно представить как стационарный случайный процесс, обладающий свойством эргодичности $[17,27]$, и тогда среднее значение по любому сечению можно заменить на среднее значение по одной достаточно продолжительной реализации и по ней можно составить представление о случайном процессе в целом. Это приводит к необходимости анализировать его методами теории периодически коррелируемых случайных процессов (сокращенно ПКСП) [20, 22-24, 26-29].
Случайный процесс $\xi(t), t \in(-\infty, \infty)$ называют периодически коррелированным, если существует фиксированное положительное число $T$, при сдвиге на которое характеристики процесса остаются инвариантными. Математическое ожидание такого процесса определяется следующим образом:

$$
m_{\xi}=M\{\xi(t+k T)\}
$$

а автокорреляционная функция как:

$$
K_{\xi}(t, \tau)=M\left\{\xi^{*}(t+k T) \xi^{*}(t+\tau+k T)\right\},
$$

где $\xi^{*}(t)=\xi(t)-m_{\xi}(t) ; \tau-$ сдвиг автокорреляционной функции, $k$ - произвольное целое число и поэтому правые части (1) и (2) не меняются при изменении $k$.

При $\tau=0$ функция (2) равна дисперсии процесса $D(t)$. Функции $m_{\xi}(t), D_{\xi}(t)$ и $K_{\xi}(t, \tau)$ являются периодическими по аргументу $t$ с периодом $T$, который называется периодом коррелированности. Естественным периодом коррелированности речного стока служит период, равный одному году. Характеристики ПКСП описывают повторяемость свойств гидрологических процессов относительно $m_{\xi}(t)$, которое характеризует регулярную компоненту изменений и позволяет найти средний многолетний образ сезонного или месячного хода и может быть интерпретировано как "норма"; дисперсия процесса $\xi(t)$ определяет отклонение от средней многолетней нормы. Анализ графиков оценок $m(t)$ и $D(t)$ дает возможность установить тип внутригодовой и межгодовой изменчивости. В случае когерентности графиков изменчивость происходит в виде амплитудной модуляции - ослабление или усиление интенсивности основных элементов внутривекового хода, тогда как в случае некогерентности - в виде наложения долгопериодного колебания или частотно-фазовой модуляции. Вид функции $K_{\xi}(t, \tau)$ определяет закономерности корреляционных зависимостей внутригодовых (при $\tau=1$ месяц) или межгодовых (при $\tau=1$ год) изменений процесса по заданным моментам времени. Оценки $m_{\xi}(t), D_{\xi}(t)$ и $K_{\xi}(t, \tau)$, вычисляются по отсчетам, взятым из исходной реализации через период коррелированности:

$$
\begin{gathered}
m_{\xi}^{*}(t)=\frac{1}{n} \sum_{k=1}^{n} \xi(t+k T), \\
D_{\xi}^{*}(t)=\frac{1}{n} \sum_{k=1}^{n}\left[\xi^{*}(t+k T)\right]^{2}, \\
K_{\xi}^{*}(t, \tau)=\frac{1}{n} \sum_{k=1}^{n}\left[\xi^{*}(t+k T) \xi^{*}(t+k T+\tau)\right] .
\end{gathered}
$$

При использовании исходной информации месячного периода осреднения оценки (3) и (5) вычисляются по ежегодным последовательно- 
Таблица 1. Основные сведения об используемых гидрологических постах

\begin{tabular}{|c|c|c|c|c|}
\hline Река & Гидрологический пост & Индекс & $\begin{array}{c}\text { Географические } \\
\text { координаты }\end{array}$ & $\begin{array}{c}\text { Период наблюдений, } \\
\text { годы }\end{array}$ \\
\hline \multicolumn{5}{|l|}{ Урал } \\
\hline \multicolumn{5}{|c|}{$\mathrm{F}=82300 \mathrm{KM}^{2}$} \\
\hline & г. Оренбург & 19063 & $51^{\circ} 41^{\prime}$ с.ш. $55^{\circ} 06^{\prime}$ в.д. & $1927-2010$ \\
\hline \multicolumn{5}{|c|}{$\mathrm{F}=17200 \mathrm{KM}^{2}$} \\
\hline & с. Кизильское & 19049 & 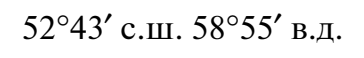 & $1931-2010$ \\
\hline \multicolumn{5}{|c|}{$\mathrm{F}=2650 \mathrm{KM}^{2}$} \\
\hline \multicolumn{2}{|c|}{ г. Верхнеуральск } & 19039 & $53^{\circ} 53^{\prime}$ с.ш. $59^{\circ} 12^{\prime}$ в.Д. & $1936-2010$ \\
\hline Сакмара & д. Верхне-Галеево & 19153 & $52^{\circ} 08^{\prime}$ с.ш. $57^{\circ} 52^{\prime}$ в.Д. & $1958-2010$ \\
\hline \multicolumn{5}{|c|}{$\mathrm{F}=4420 \mathrm{KM}^{2}$} \\
\hline & д. Акъюлово & 19154 & $51^{\circ} 53^{\prime}$ с.ш. $57^{\circ} 32^{\prime}$ в.д. & $1943-2010$ \\
\hline \multicolumn{5}{|c|}{$\mathrm{F}=334 \mathrm{KM}^{2}$} \\
\hline Зилаир & c. Зилаир & 19167 & $52^{\circ} 13^{\prime}$ с.ш. $57^{\circ} 24^{\prime}$ в.д. & $1950-2010$ \\
\hline \multicolumn{5}{|c|}{$\mathrm{F}=1870 \mathrm{KM}^{2}$} \\
\hline Большой Ик & с. Мраково & 19172 & $52^{\circ} 43^{\prime}$ с.ш. $56^{\circ} 38^{\prime}$ в.Д. & $1952-2010$ \\
\hline \multicolumn{5}{|c|}{$\mathrm{F}=54.4 \mathrm{KM}^{2}$} \\
\hline Карагайлы & д. Старосибаево & 19111 & 52॰42’ с.ш. $58^{\circ} 33^{\prime}$ в.д. & $1949-2010$ \\
\hline \multicolumn{5}{|c|}{$\mathrm{F}=1830 \mathrm{KM}^{2}$} \\
\hline Большой Кизил & д. Верхнеабдряшево & 19108 & $52^{\circ} 57^{\prime}$ с.ш. $58^{\circ} 46^{\prime}$ в.Д. & $1949-2010$ \\
\hline \multicolumn{5}{|c|}{$\mathrm{F}=212 \mathrm{KM}^{2}$} \\
\hline & с. Бурангулово & 19106 & $53^{\circ} 2^{\prime}$ с.ш. $58^{\circ} 20^{\prime}$ в.Д. & $1954-2010$ \\
\hline \multicolumn{5}{|c|}{$\mathrm{F}=503 \mathrm{KM}^{2}$} \\
\hline Малый Кизил & д. Муракаево & 1902 & 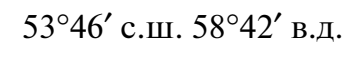 & $1959-2010$ \\
\hline \multicolumn{5}{|c|}{$\mathrm{F}=785 \mathrm{KM}^{2}$} \\
\hline Миндяк & д. Новобайрамгулово & 19087 & $54^{\circ} 06^{\prime}$ с.ш. $59^{\circ} 03^{\prime}$ в.Д. & $1954-2010$ \\
\hline \multicolumn{5}{|c|}{$\mathrm{F}=1750 \mathrm{KM}^{2}$} \\
\hline Таналык & с. Самарское & 19122 & $52^{\circ} 02^{\prime}$ с.ш. $58^{\circ} 090^{\prime}$ в.Д. & $1957-2010$ \\
\hline \multicolumn{5}{|c|}{$\mathrm{F}=3270 \mathrm{KM}^{2}$} \\
\hline & д. Мамбетово & 19123 & $51^{\circ} 52^{\prime}$ с.ш. $58^{\circ} 27^{\prime}$ в.Д. & $1961-2010$ \\
\hline
\end{tabular}

стям значений для каждого месяца года, в предположении стационарности таковых.

Прогнозирование временно́го ряда среднемесячных расходов воды состоит в декомпозиции такового на трендовую, периодическую (циклическую) и случайную компоненты. Предлагаемый метод прогнозирования предполагает аддитивное представление анализируемых рядов [4], в соответствии с которым исходный ряд можно представить в виде:

$$
\xi(t)=\xi_{\mathrm{T}}(t)+\xi_{\mathrm{C}}(t),
$$

где $\xi_{\mathrm{T}}(t)$ - трендовая, а $\xi_{\mathrm{C}}(t)-$ стохастическая компонента. Стохастическая компонента в рамках предлагаемого метода включает в себя и цик- лическую составляющую. Трендовая компонента адекватно описывается обыкновенным линейным уравнением и содержит только линейные параметры. Критерий качества прогноза $\varepsilon(t)$ определяется как минимизируемый средний квадрат ошибки прогнозирования.

Постановка задачи прогнозирования предполагает, что на выходе модели необходимо получить заданный требуемый выходной сигнал $\xi(t+\gamma)$, равный сформированному на интервале $\gamma$ выходному сигналу. Если на вход оптимизируемой модели в интервале $\left(t_{0}, t\right)$ поступает сигнал $\xi(t)$ с известными статистическими характеристиками, то реализуя некоторое преобразование $A$ входного сигна- 
ла, система формирует выходной сигнал следующим образом [32-34]:

$$
Y(t)=A\{\xi(t)\} .
$$

Ограничивая поиск оптимального по условию (7) оператора классом линейных, физически реализуемых, нестационарных операторов, получим:

$$
Y(t)=\int_{t_{0}}^{t} a(t, \tau) \xi(\tau) d \tau,
$$

где $a(t, \tau)-$ импульсная весовая функция оптимальной системы, из условия минимума критерия среднего квадрата ошибки можно вывести интегральное уравнение Винера [29] для оптимального прогнозирующего устройства на интервал прогнозирования $\gamma$ :

$$
\int_{t_{0}}^{t} \alpha\left(t, t_{2}\right) K_{\xi}\left(t_{2}, t_{1}\right) d t_{2}=K_{\xi}\left(t+\gamma, t_{1}\right), t_{0} \leq t_{1} \leq t .
$$

Подстановка в уравнение (9) автокорреляционной функции ПКСП (5) позволяет получить импульсную весовую функцию оптимальной прогнозирующей линейной системы, с учетом регулярных стохастических периодических компонент. Дискретизируя выражение (8), получаем оптимальное по критерию минимума среднего квадрата ошибки уравнения прогноза процесса $\xi(t)$ из точки $i$ на интервале $\gamma$ с помощью линейного экстраполятора, учитывающего $n+1$ значение реализации процесса:

$$
Y\left(t_{i}\right)=\sum_{k=0}^{n} \alpha_{k}(\gamma) \xi *\left(t_{i-k}\right),
$$

где коэффициенты $\alpha_{k}(\gamma)$ определяются из системы линейных уравнений.

Сопутствующие вычислительные процедуры (1-10) модели ПКСП и основанной на ней прогнозирующей системы были реализованы в [30].

\section{РЕЗУЛЬТАТЫ И ОБСУЖДЕНИЕ}

Графики оценок вероятностных характеристик ПКСП по наиболее характерным ГП приведены на рис. 1. Необходимо отметить, что по всем 14 ГП графики $m^{*}(t)$ имеют вид одновершинной кривой с основным максимумом, приходящимся на период весеннего половодья (IV-V месяцы), и с незначительными пиками летней и зимней межени в VI-VII месяцы и IX-XI месяцы соответственно, что свидетельствует о паводочном режиме рек рассматриваемого бассейна. Кривые $D^{*}(t)$ для всех используемых в анализе ГП повторяют особенности кривых $m^{*}(t)$, что свидетельствует о межгодовой изменчивости гидрологических процессов, преимущественно проявляющихся в виде амплитудной модуляции характерных элементов внутригодового хода.

Для установления степени пространственных связей во внутригодовом распределении стока данные инструментальных наблюдений по каждому из четырнадцати ГП коррелировались между собой на временно́м интервале 1961-2010 гг. Результат пространственной корреляции по выделенным гидрологическим сезонам и среднегодовым значениям стока в бассейне р. Урал представлен на рис. 2. Видно, что статистически значимые величины коэффициента корреляции $(r \geq 0.37$, при длине ряда $n=50$ и доверительном интервале $p=$ $=0.001) \mathrm{c}$ большинством ГП наблюдаются у ГП г. Оренбург - р. Урал, как по сезонам, так и по среднегодовым значениям. Наиболее слабая теснота связи по всем постам выявлена с ГП г. Зилаир p. Зилаир, как по среднегодовым, так и посезонным значениям стока, что объясняется особенностью физико-географических условий, прежде всего пористостью пород, слагающих Зилаирское плато, по которому протекает река, а также строительством водохранилища в 2007 г. С учетом выше изложенного обсуждения результаты вычислительных процедур метода ПКСП и прогностической системы приведены на примере ГП р. Урал - г. Оренбург, являющимся замыкающим створом для всех 13 гидрологических постов и в определенном смысле репрезентативным для всего бассейна реки. Основные статистические характеристики ГП p. Урал - г. Оренбург показаны на рис. 3.

В качестве примера на рис. 4а и 4 п приведены диаграммы $K^{*}(t, \tau), \tau=1$ мес. и $\tau=1,2,3,4$ и 5 лет, соответственно, по ГП р. Урал - г. Оренбург. Необходимо отметить, что функции $K^{*}(t, \tau)$ при $\tau=1$ мес. и $\tau=1$ год имеют две ветви связей “вперед” и “назад”. Ветвь связи “вперед” показывает влияние значений стока в данный месяц года на значения в последующие месяцы, а ветвь связей “назад” показывает, как значения стока в данный месяц года зависят от значений стока в предшествующие месяцы. Идентичность диаграмм оценок корреляционных зависимостей внутригодовой изменчивости речного стока $K^{*}(t, \tau)$ при $\tau=1$ мес., позволяет говорить о влиянии регулирующей роли каскада водохранилищ (Верхнеуральское, Магнитогорское и Ириклинское), что приводит к увеличению внутригодовой коррелированности процесса. Так, радиус корреляции связей “вперед” и “назад" составляют 5-6 мес. для среднегодовых значений стока и большинства месяцев года, за исключением марта, апреля и мая. Значения коэффициентов линейной корреляции $r$ в такие полугодовые периоды устойчивых связей как “вперед”, так и “назад” являются статистически значимыми и варьируются от 0.50 до 0.98. Диаграммы оценок корреляционных зависимостей межгодовой изменчивости $K^{*}(t, \tau)$ стока для всех месяцев года достаточно быстро затухают на начальном 

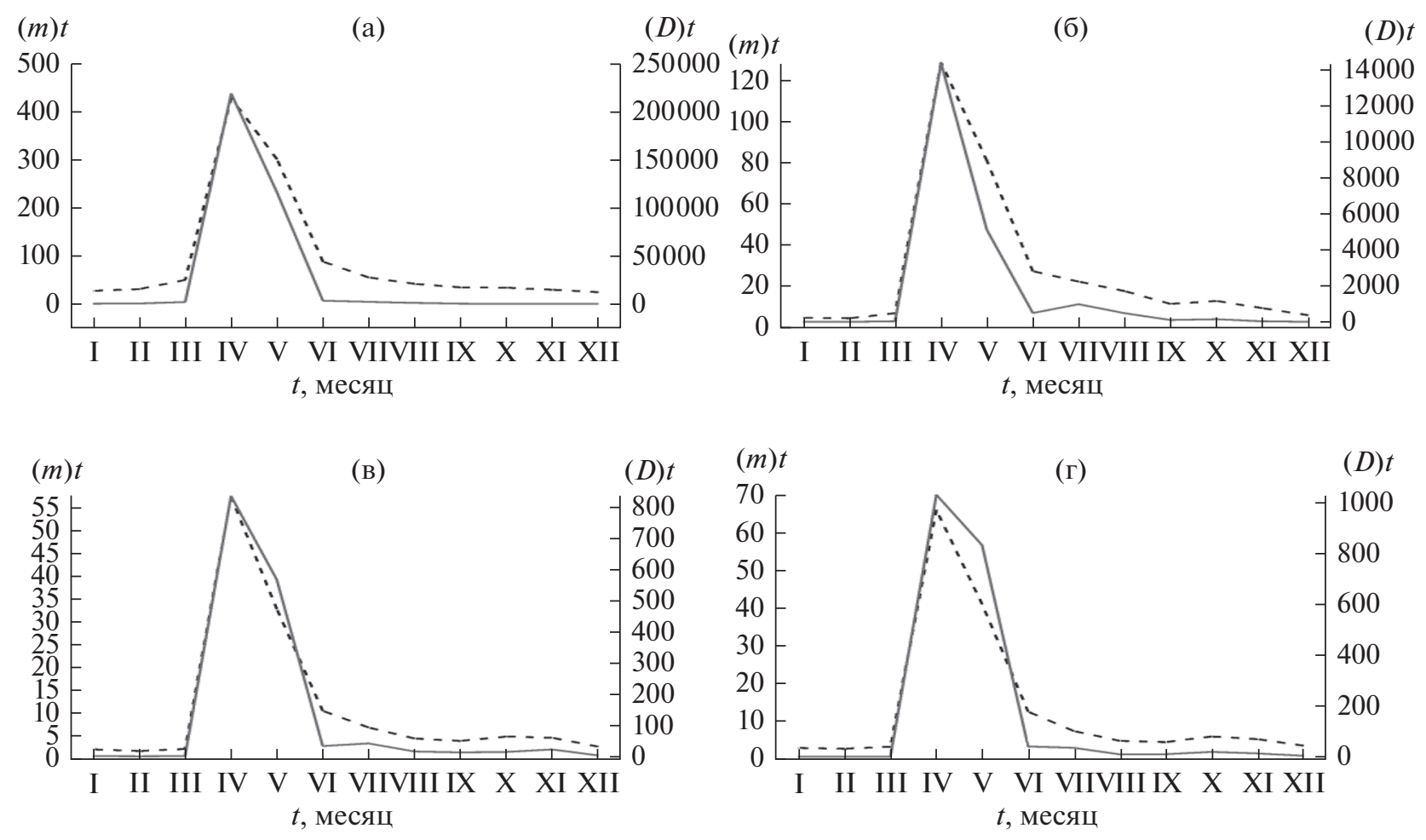

Рис. 1. Оценки математического ожидания $m(t)$ - серая сплошная, и дисперсии $D(t)$ - черная пунктирная, внутригодового хода расхода воды в бассейне р. Урал по ГП: (а) р. Урал - г. Оренбург, (б) р. Урал - с. Кизильское, (в) р. Сакмара д. Верхне-Галеево, (г) р. Сакмара - д. Акъюлово.

участке коррелограммы. Для среднегодовых значений стока и отдельных месяцев года (с января по июнь включительно) $K^{*}(t, \tau)$ имеют вид затухающей экспоненты, а для некоторых месяцев (июль-декабрь) - затухающей косинусоиды. При этом радиус корреляции для большинства месяцев года не превышает 1-2 года, а коэффициенты корреляции в большинстве случаев являются статистически незначимыми, поскольку их максимальные значения не превышают 0.45.

Наличие ритмики годовой цикличности (рис. 5а) и проведенный вейвлет-анализ среднемесячных расходов воды (рис. 5б, в) позволяет выявить следующие циклы водности, которые условно можно разделить на высокочастотные с периодами в $1,0.5$ и 0.25 года и меньше и низкочастотные с продолжительностью 5, 11 и 22 года. Первые относятся к внутригодовым циклам и обусловлены вращением Земли вокруг Солнца, вторые - к внутривековым и являются результатом более сложного взаимодействия системы "атмосфера-гидросфера". На рис. $5 б$ показана временная локализация выявленных циклов, а черным контуром обведены статистически значимые периоды и “конус влияния" с учетом длины анализируемого ряда данных в пределах 95\% доверительной вероятности, по аналогии с [35]. Соответствующие циклы также отмечены на спектре мощности (рис. 5в), который показывает вклад каждого из выявленных циклов водности при декомпозиции сигнала. Локализация высокочастотных составляющих отмечена на всем анализируемом периоде инструментальных наблюдений, а низкочастотные составляющие являются статистически значимыми на отдельных временных интервалах с 1920-х до середины 1960-х годов (см. рис. 5б).

Следует отметить, что к концу 1960 -х годов были введены в эксплуатацию все три водохранилища в бассейне р. Урал, расположенные выше створа ГП г. Оренбург, и речной сток был зарегулирован. Спектральный анализ среднегодовых значений речного стока установил преобладание низкочастотной составляющей сигнала, что наглядно показано в работе [13].

Реакция стока в бассейне р. Урал на потепление климата в исследуемом регионе оказалась не столь однозначна. В общем случае повышение температуры воздуха ведет к уменьшению стока, однако в реальных условиях все не так очевидно. В соответствии с инструментальными наблюдениями среднегодовая температура воздуха, как и температура в отдельные сезоны на Южном Урале в последние десятилетия характеризовались тенденцией роста, а речной сток в среднем по бассейну также увеличивался. При этом произо- 

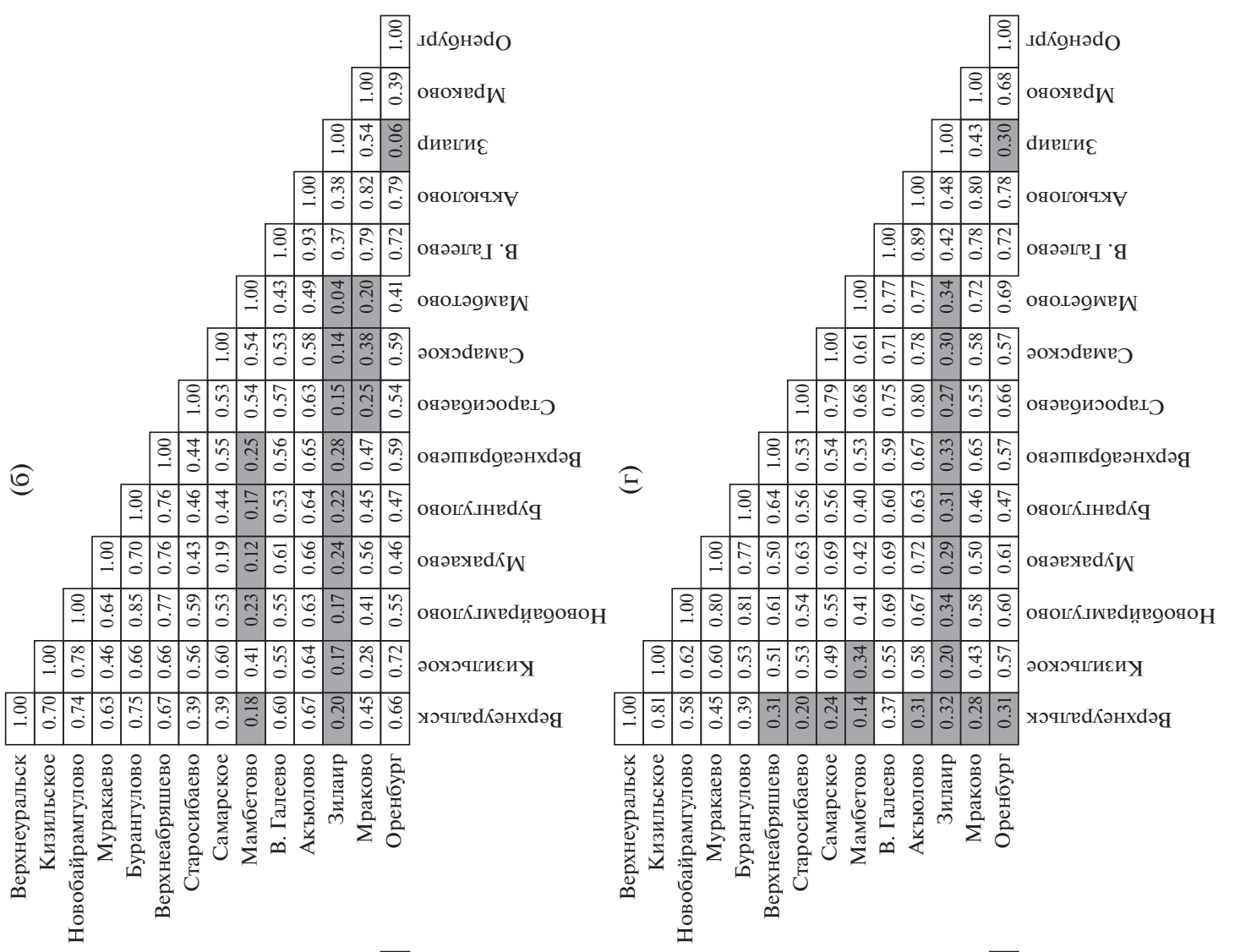

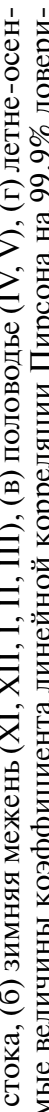
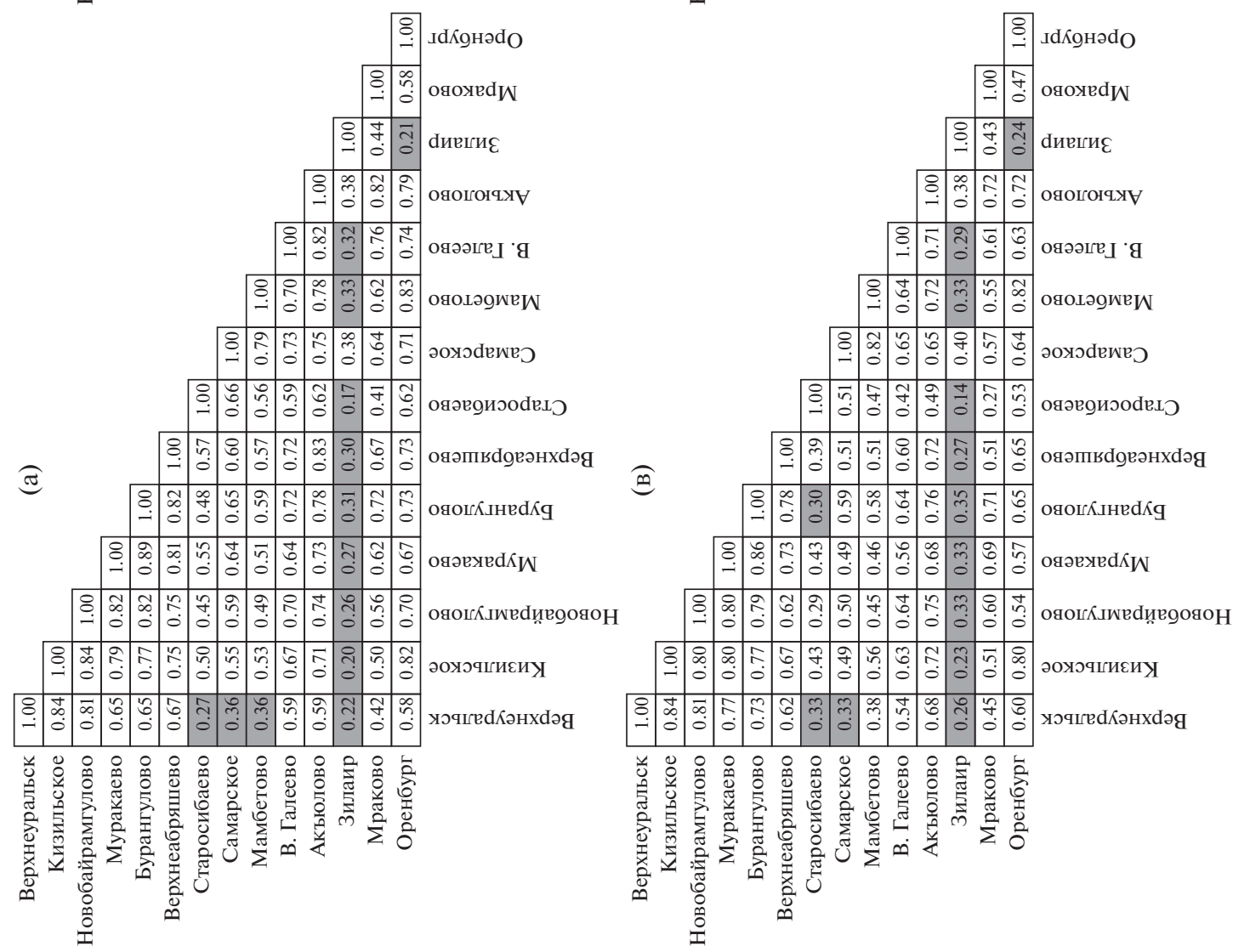

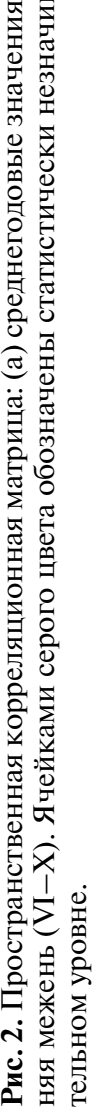




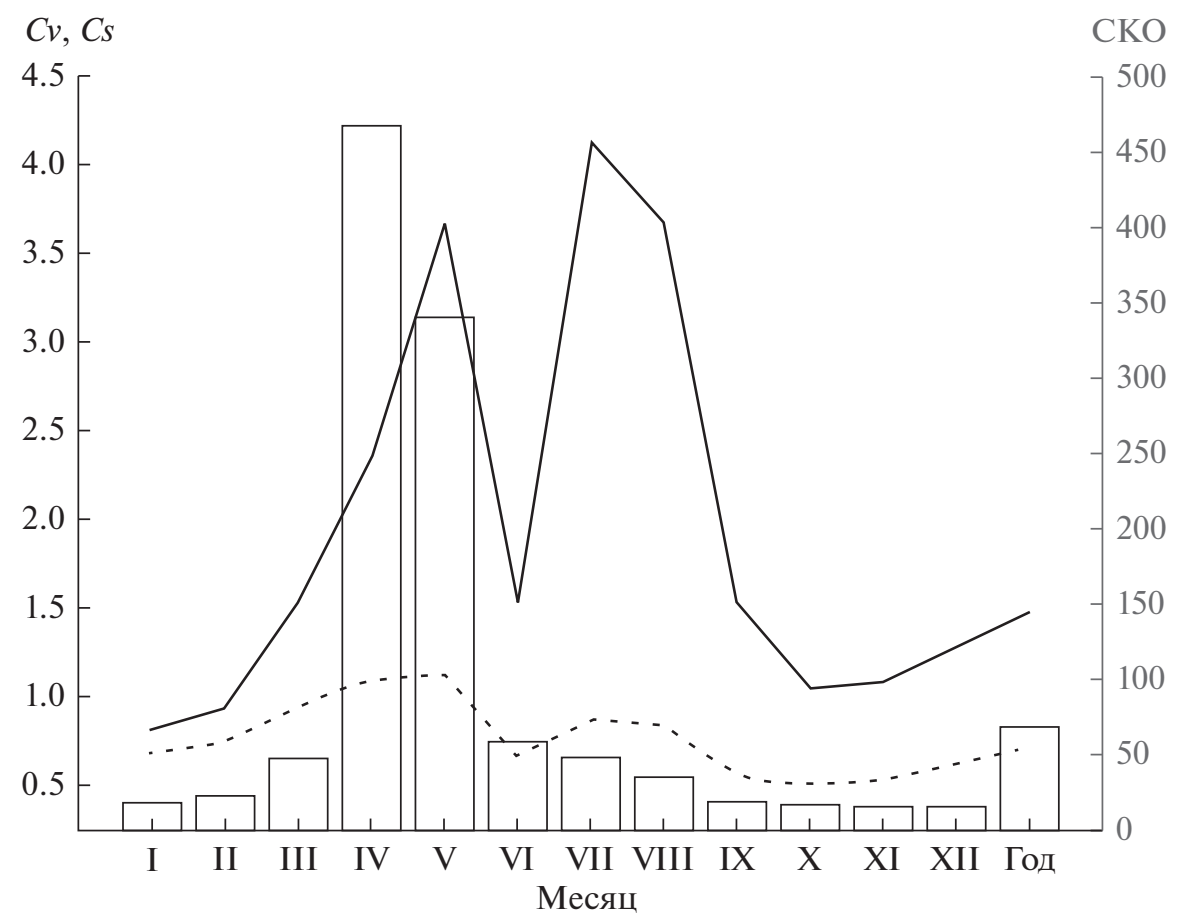

Рис. 3. Статистические характеристики месячного и годового стока р. Урал по ГП г. Оренбург. Прямоугольниками показано среднеквадратическое отклонение (шкала справа), сплошной черной линией - значения $C s$, пунктирной линией - значения $C \mathrm{v}$ (шкала слева).

шли изменения во внутригодовом распределении стока: доля весеннего стока начала сокращаться, сток летне-осенней межени вырос, а зимний сток не изменился. Согласно [21], необходимо учитывать, если повышение температуры обусловлено ростом в холодный период, то это сопровождается увеличением атмосферных осадков, поверх- ностного и подземного стока. Рост температуры в теплый период, напротив, приводит к увеличению дефицита влажности воздуха, испарения и уменьшению осадков и стока. Влияние потепления климата на сток рек будет находить свое отражение в усилении контраста между различными физико-географическими зонами [18, 19].

Таблица 2. Статистические характеристики прогностической системы на основе модели ПКСП по сезонам на примере ГП г. Оренбург - р. Урал. Числитель - фактические значения, знаменатель - значения по модели

\begin{tabular}{l|c|c|c}
\hline \multirow{2}{*}{ Характеристика } & \multicolumn{3}{|c}{ Расход воды } \\
\cline { 2 - 4 } & $\begin{array}{c}\text { 3имняя межень } \\
\text { (XI, ХII, I, II, III) }\end{array}$ & $\begin{array}{c}\text { Весеннее половодье } \\
\text { (IV, V) }\end{array}$ & $\begin{array}{c}\text { Летне-осенняя межень } \\
\text { (VI-X) }\end{array}$ \\
\hline Среднее, $\mathrm{m}^{3} \mathrm{c}^{-1}$ & $32.54 / 32.51$ & $364.14 / 352.25$ & $50.84 / 49.73$ \\
$C_{\mathrm{v}}$ & $0.65 / 0.65$ & $0.91 / 0.94$ & $0.58 / 0.58$ \\
$C_{\mathrm{s}}$ & $0.71 / 0.73$ & $1.9 / 2.2$ & $1.3 / 1.4$ \\
$r^{*}$ & 90 & 56 & 66 \\
\hline
\end{tabular}

*r- значение коэффициента линейной корреляции между модельными и фактическими значениями сезонного стока. 


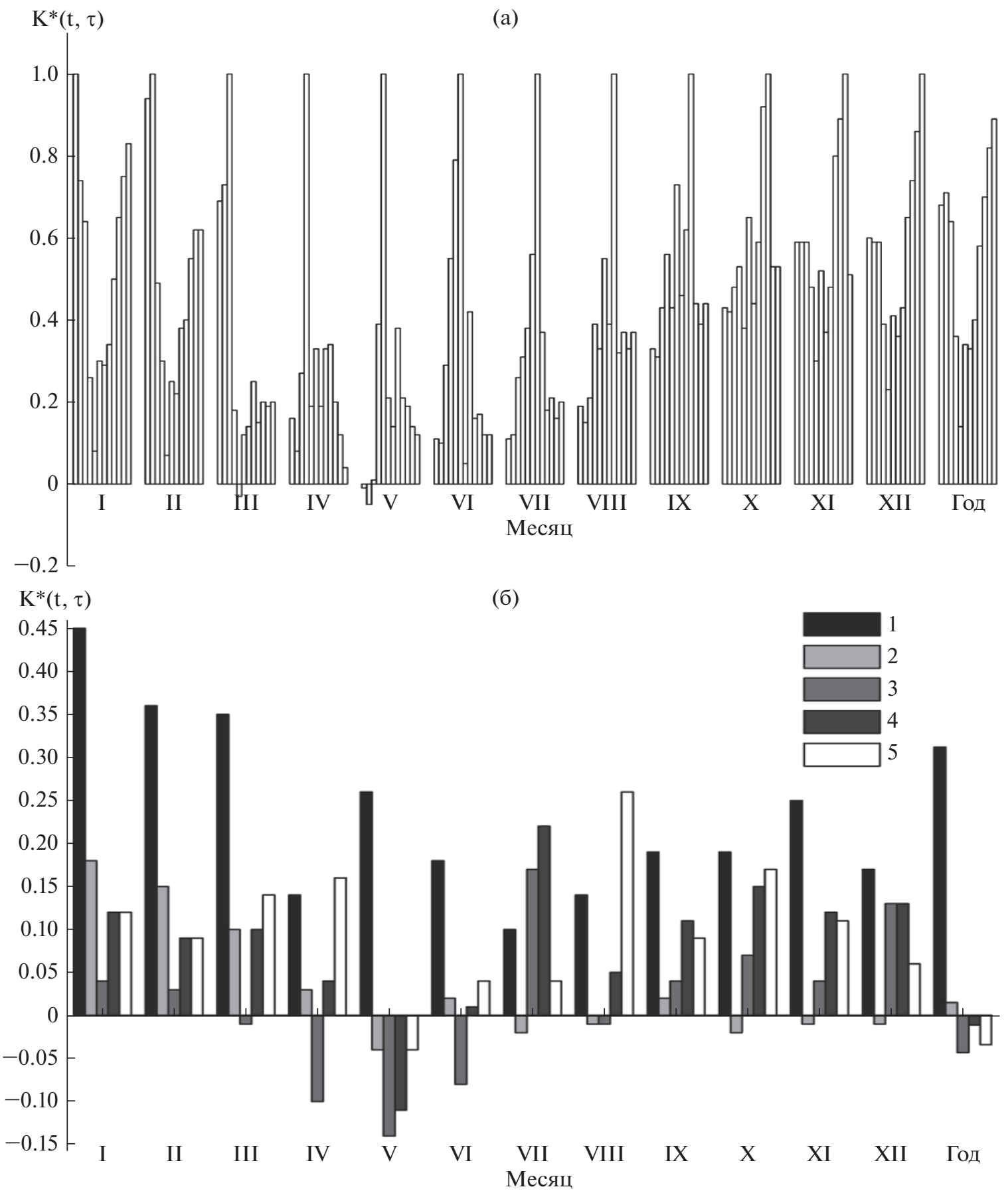

Рис. 4. Автокорреляционная функция внутригодовой изменчивости расхода воды (а) и межгодовой изменчивости расхода воды (б) по ГП р. Урал - г. Оренбург. Арабскими цифрами и соответствующими цветами обозначен сдвиг/лаг на $1,2,3,4$ и 5 лет.

Результаты моделирования на основе метода ПКСП речного стока по гидрологическим сезонам представлены в табл. 2. Как видно из данных табл. 2, реализованная прогностическая система обеспечивает приемлемое качество моделирова- ния; нормы стока, коэффициенты вариации и асимметрии модельных данных практически равны фактическим, и величина обеспеченности допустимой погрешности $P$, в соответствие с [6], позволяют считать качество прогнозов меженно- 


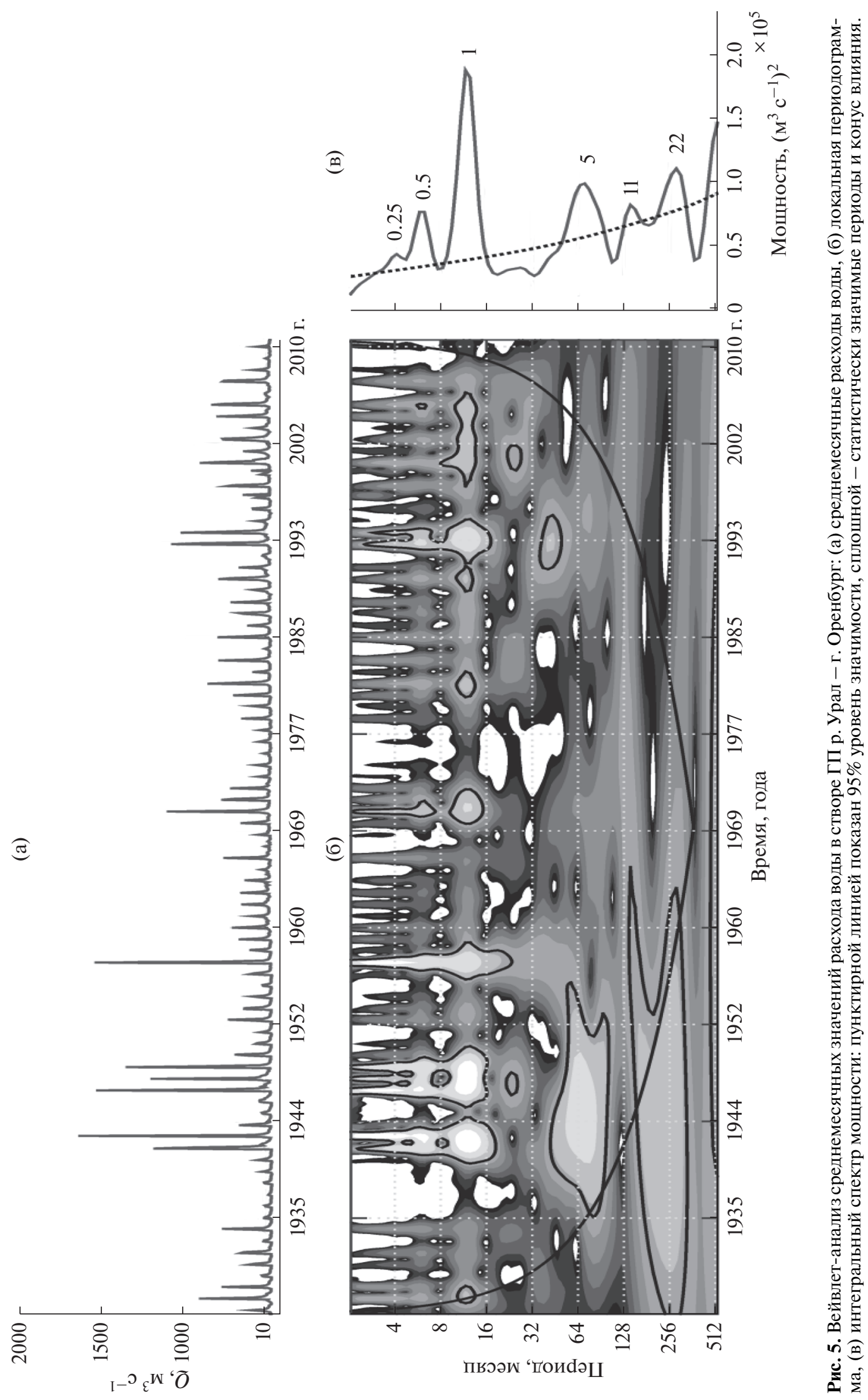


го стока приемлемыми. Анализ гистограмм плотности распределений среднемесячных значений стока по выделенным сезонам показал, что для аппроксимации этих плотностей можно использовать бета-распределение.

\section{ВЫВОДЫ}

Выполненный анализ корреляционных зависимостей внутригодовой $\left(K^{*}(t, \tau), \tau=1\right.$ мес.) и межгодовой $\left(K^{*}(t, \tau), \tau=1,2,3,4\right.$ и 5 лет) изменчивости стока в бассейне р. Урал показал, что для него характерна существенно большая коррелированность значений внутри года по сравнению с межгодовой. Выявленная специфика объясняется наличием во временно́й структуре процесса долгопериодного колебания стока, на фоне которого проявляется ритмика годовой и внутригодовой цикличности. Можно рассматривать колебания стока в бассейне р. Урал как случайный стохастический процесс, состоящий из двух компонент инерционной (трендовая) и сезонной (осциллирующая). Разработана прогностическая система на основе модели речного стока, как ПКСП. Ее применение дало удовлетворительные результаты по двум выделенным гидрологическим сезонам: зимней и летне-осенней межени. Объяснение таких результатов по зимнему и летне-осеннему сезонам основано на явлении инерционности речного стока. Наиболее сложным для предсказания является сток апреля и мая, который сильно зависит от погодных условий и определяется в основном осадками осенне-зимнего периода. В случае ранней весны в апреле на малых реках уже начинается половодье, а в случае сохранения зимних условий продолжается зимняя межень. Результаты и методические рекомендации, полученные в данной работе, возможно, могут быть использованы в целях гидрологического прогнозирования меженного стока.

\section{ФИНАНСИРОВАНИЕ}

Работа выполнена при поддержке РНФ (грант № 19-17-00215).

\section{БЛАГОДАРНОСТИ}

Авторы выражают искреннюю признательность анонимным рецензентам, сделавшим ряд ценных замечаний, а также Башкирскому УГМС, Оренбургскому ЦГМС (филиал Приволжского УГМС Росгидромета), лично Н.А. Бондаренко и В.3. Горохольской за предоставленные данные по инструментальным наблюдениям по расходам воды.

\section{FUNDING}

The study was financially supported by the Russian Science Foundation (project no. 19-17-00215).

\section{ACKNOWLEDGMENTS}

Authors are grateful to anonymous reviewers for valuable comments, as well as Bashkir Department of Hydrometeorology and Environmental Monitoring, Orenburg Center of Hydrometeorology and Environmental Monitoring, N.A. Bondarenko, and V.Z. Gorohol'skaya for data on instrumental observations of water discharge.

\section{СПИСОК ЛИТЕРАТУРЫ}

1. Андреянов В.Г. Внутригодовое распределение речного стока. Л.: Гидрометеоиздат, 1960. 327 с.

2. Андреянов В.Г. Методические указания по расчетам внутригодового распределения стока при строительном проектировании. Л.: Гидрометеоиздат, $1970.77 \mathrm{c}$.

3. Андреянов В.Г. Некоторые уточнения и упрощения методики расчетов календарного внутригодового распределения речного стока применительно к требованиям строительного проектирования // Труды ГГИ. Л.: Гидрометеоиздат, 1966. Вып. 134. C. $80-114$.

4. Бендат Джк., Пирсол А. Прикладной анализ случайных данных. М.: Мир, 1989. 540 с.

5. Болгов М.В., Филиппова И.А. Пороговые стохастические модели минимального стока // Метеорология и гидрология. 2006. № 3. С. 88-94.

6. Борш С.В., Христофоров А.В. Гидрометеорологические прогнозы // Труды ГМЦ России. 2015. № 355. С. $48-100$.

7. Васильев Д.Ю., Бабков О.К., Давлиев И.Р., Семенов В.А., Христодуло О.И. Пространственно-временная структура колебаний приземной температуры на Южном Урале // Оптика атмосферы и океана. 2018. Т. 31. № 4. C. 294-302.

8. Васильев Д.Ю., Бабков О.К., Кочеткова Е.С., Семенов B.A. Вейвлет и кросс-вейвлет анализ сумм атмосферных осадков и приповерхностной температуры на Европейской территории России // Изв. РАН. Сер. геогр. 2017. № 6. С. 63-77.

9. Васильев Д.Ю., Великанов Н.В., Водопьянов В.В., Красногорская Н.Н., Семенов В.А., Христодуло О.И. Связь аномалий яркостной температуры нижней тропосферы с климатическими индексами на примере Южного Урала // Исслед. Земли из космоса. 2019. № 2. C. 14-28.

10. Васильев Д.Ю., Гавра Н.К., Кочеткова Е.С., Ферапонтов Ю.И. Корреляции сумм атмосферных осадков со средними и максимальными расходами воды весеннего половодья в бассейне реки Белая // Метеорология и гидрология. 2013. № 5. С. 351-358.

11. Васильев Д.Ю., Лукманов Р.Л., Ферапонтов Ю.И., Чувыров А.Н. Цикличность гидрометеорологических характеристик на примере Башкирии // ДАН. 2012. T. 447. № 3. С. 331-334.

12. Васильев Д.Ю., Павлейчик В.М., Семенов В.А., Сивохип Ж.T., Чибилев А.A. Многолетний режим темпе- 
ратуры воздуха и атмосферных осадков на территории Южного Урала // ДАН. 2018. Т. 478. № 2. C. $245-249$. https://doi.org/10.7868/S0869565218050201

13. Васильев Д.Ю., Сивохип Ж.Т., Чибилев А.А. Динамика климата и внутривековые колебания стока в бассейне реки Урал // ДАН. 2016. Т. 469. № 1. C. $710-715$.

14. Васильев Д.Ю., Ферапонтов Ю.И. Тренды в колебаниях приземной температуры воздуха на примере Башкирии // Изв. РАН. Сер. геогр. 2015. № 1. С. 77-86.

15. Васильев Д.Ю., Водопьянов В.В, Зайцева Г.С., Закирзянов Ш.И., Семенов В.А., Сивохип Ж.Т., Чибилев А.А. Модель долгосрочного прогноза весеннего стока на примере реки Белая // ДАН. 2019. Т. 486. № 6. C. $723-726$. https://doi.org/10.31857/S0869-56524866723-726

16. Водные ресурсы России и их использование / под ред. И.А. Шикломанова. СПб.: изд-во ГГИ, 2008. $600 \mathrm{c}$.

17. Гельфанд И.М., Фомин С.В. Вариационное исчисление. М.: Физматлит, 1961. 228 с.

18. Добровольский С.Г. Проблема глобального потепления и изменения стока российских рек // Водные ресурсы. 2007. Т. 34. № 6. С. 643-655.

19. Долгов С.В., Коронкевич Н.И. Особенности реакции рек Русской равнины на изменение температуры воздуха // Изв. РАН. Сер. геогр. 2012. № 6. С. 55-62.

20. Картвелишвили Н.А. Стохастическая гидрология. Л.: Гидрометеоиздат, 1975. 162 с.

21. Коронкевич Н.И., Барабанова Е.А., Зайцева И.С. Влияние изменения годовых значений температуры воздуха и осадков на сток рек Русской равнины // Изв. РАН. Сер. геогр. 2007. № 5. С. 64-70.

22. Мякишева Н.В., Гоюй Ч. Ритмика годовой цикличности гидрологических процессов в районах с интенсивной хозяйственной деятельностью // Вестн. СПбГУ. Сер. 7. 2011. Вып. 1. С. 98-106.

23. Мякишева Н.В., Трапезников Ю.А. Авторегрессионная модель межгодовой изменчивости гидрометеорологических процессов // Вероятностный анализ и моделирование океанологических процессов. Л.: Гидрометеоиздат, 1984. С. 31-39.
24. Музылев С.В., Привальский В.Е., Раткович Д.Я. Стохастические модели в инженерной гидрологии. М.: Наука, 1982. 184 с.

25. Раткович Д.Я. Многолетние колебания речного стока: закономерности и регулирование. Л.: Гидрометеоиздат, 1976. $255 \mathrm{c}$.

26. Раткович Д.Я., Болгов М.В. Стохастические модели колебаний составляющих водного баланса речного бассейна. М.: ИВП РАН, 1997. $261 \mathrm{c.}$

27. Рожков B.A. Теория и методы статистического оценивания вероятностных характеристик случайных величин и функций с гидрометеорологическими примерами. СПб.: Гидрометеоиздат, 2001. $340 \mathrm{c}$.

28. Румянцев В.А., Трапезников Ю.А. Стохастические модели гидрологических процессов. СПб.: Наука, 2008. $152 \mathrm{c}$.

29. Сванидзе Г.Г. Математическое моделирование гидрологических рядов. Л.: Гидрометеоиздат, 1977. 293 с.

30. Свидетельство о государственной регистрации программы для ЭВМ 2018661796. РФ. Реализация метода периодически коррелируемого случайного процесса, на примере стока реки / ред. Д.Ю. Васильев, В.В. Водопьянов, Ш.Н. Закирзянов; правообладатель Уфимск. гос. авиац. техн. ун-т. № 2018618838; заявл. 17.08.2018.; зарегистр. 18.09.2018.

31. Чибилев А.А. Река Урал. Л.: Гидрометеоиздат, 1987. $168 \mathrm{c}$.

32. Hao Z., Singh V.P. Entropy-copula method for singlesite monthly streamflow simulation // Wat. Res. 2012. V. 48. W06604. https://doi.org/10.1029/2011WR011419

33. Ricker Dennis W. Echo Signal Processing. Springer, 2003. 240 p.

34. Salvadori G., Michele C.D. Multivariate multiparameter extreme value models and return periods: a copula approach // Wat. Res. 2010. V. 46. W10501. https://doi.org/10.1029/2009WR009040

35. Torrence C., Campo G.P. A practical guide to wavelet analysis // Bull. Amer. Met. Soc. 1998. V. 79. P. 61-78.

36. Wen X., Tang G., Wang S., Hnang J. Comparison of global mean temperature series // Advances in Climate Change Res. 2011. V. 2. № 4. P. 187-192.

\title{
Correlation of the Monthly and Annual Runoff Multiple-Year Variation in the Ural River Basin
}

\author{
D. Yu. Vasil'ev', 2, \#, V. V. Vodopyanov' ${ }^{1}$ Sh. I. Zakirzyanov' ${ }^{1}$, A. Zh. Kenzhebaeva ${ }^{3}$, \\ V. A. Semenov ${ }^{2,4}$, and Zh. T. Sivokhip ${ }^{5}$ \\ ${ }^{1}$ Ufa State Aviation Technical University, Ufa, Russia \\ ${ }^{2}$ Institute of Atmospheric Physics, Russian Academy of Sciences, Moscow, Russia \\ ${ }^{3}$ Lomonosov Moscow State University, Moscow, Russia \\ ${ }^{4}$ Institute of Geography, Russian Academy of Sciences, Moscow, Russia \\ ${ }^{5}$ Institute of Steppe, Ural Branch of Russian Academy of Sciences, Orenburg, Russia \\ \#e-mail: vasilevdy@ugatu.su
}

This article examines the strength of perennial fluctuations' relationship in monthly and annual runoffs in the Ural River basin. The norms of monthly and annual runoffs were calculated for the rivers of this basin. 
Using the wavelet analysis method, trends of their changes and water flow cycles were identified. An estimation of the river flow spatial correlation within the studied river basin was made. On the basis of a periodically correlated process model, the time series was predicted for the selected hydrological seasons. The relationship strength between the monthly average discharge of each month and the average annual water discharge, as well as between the average monthly water discharges were estimated. The statistical significance of the identified correlations was determined. A significantly stronger correlation between the values of the runoff within the year in comparison to that of the interannual was established. The last finding may be due to the longperiod oscillation presence in the temporal series that helps manifest the rhythm of the annual and intra-annual cycles. It is proposed to consider the runoff fluctuations in the Ural River basin as a random stochastic process consisting of two components: inertial (trend) and seasonal (oscillating).

Keywords: water discharge, runoff, Ural River, correlation links, wavelet analysis, South Ural

\section{REFERENCES}

1. Andreyanov V.G. Vnutrigodovoe raspredelenie rechnogo stoka [Intra-annual Distribution of River Flow]. Leningrad: Gidrometeoizdat, 1960.327 p.

2. Andreyanov V.G. Metodicheskie ukazaniya po raschetam vnutrigodovogo raspredeleniya stoka pri stroitel'nom proektirovanii [Guidelines for the Calculation of the Intra-Annual Distribution of Runoff During Construction Design]. Leningrad: Gidrometeoizdat, 1970. 77 p.

3. Andreyanov V.G. Nekotorye utochneniya i uproshcheniya metodiki raschetov kalendarnogo vnutrigodovogo raspredeleniya rechnogo stoka primenitel'no $k$ trebovaniyam stroitel'nogo proektirovaniya [Some Clarifications and Simplifications of the Method for Calculating the Calendar Intra-Annual Distribution of River Flow in Relation to the Requirements of Building Design]. Trudy GGI. Leningrad: Gidrometeoizdat, 1966, vol. 134, pp. 80-114.

4. Bendat J., Pirsol A. Prikladnoi analiz sluchainykh dannykh [Applied Analysis of Random Data]. Moscow: Mir Publ., 1989. 540 p.

5. Bolgov M.V., Filippova I.A. Threshold stochastic models of low flow. Meteorologiya i Gidrologiya, 2006, no. 3, pp. 88-94. (In Russ.).

6. Borshch S.V., Khristoforov A.V. Gidrometeorologicheskie prognozy [Hydrometeorological Forecasts]. Trudy GMC of Russia. Moscow: Gidrometeoizdat, 2015, no. 356 , pp. $48-100$.

7. Vasil'ev D.Yu., Babkov O.K., Davliev I.R., Semenov V.A., Christodulo O.I. Spatio-temporal stricture of surface air temperature fluctuations in the Southern Urals. Optika Atmosfery $i$ Okeana, 2018, vol. 31, no. 4, pp. 294-302. (In Russ.).

8. Vasil'ev D.Yu., Babkov O.K., Kochetkova E.S., Semenov V.A. Wavelet and cross-wavelet analysis of the sums atmospheric precipitation and air temperature in European Russia. Izv. Akad. Nauk, Ser. Geogr., 2017, no. 6, pp. 63-77. (In Russ.).

9. Vasil'ev D.Yu., Velikanov N.V., Vodopyanov V.V., Krasnogorskaya N.N., Semenov V.A., Christodulo O.I. Relationship of the brightness anomalies of the lower troposphere with the climate indices on the Southern Urals. Issledovanie Zemly iz Kosmosa, 2019, no. 2, pp. 14-28. (In Russ.).

10. Vasil'ev D.Yu., Gavra N.K., Kochetkova E.S., Ferapontov Yu.I. Correlation between the total precipitation and the mean and maximum runoff during the snowmelt flood in the Belaya River basin. Russian Meteorology and Hydrology, 2013, no. 5, pp. 351-358.

11. Vasil'ev D.Yu., Lukmanov R.L., Ferapontov Yu.I., Chuvyrov A.N. Periodicity in the hydrometeorological parameters of Bashkiria. Doklady Earth Sciences, 2013, vol. 448, no. 1, pp. 131-134. doi: 10.1134/S1028334X12110165

12. Vasil'ev D.Yu., Pavleychik V.M., Semenov V.A., Sivohip J.T., Chibilev A.A. The long-term pattern of temperature and precipitation in the Southern Ural. Doklady Earth Sciences, 2018, vol. 478, no. 2, pp. 245-249. doi: 10.7868/S0869565218050201

13. Vasil'ev D.Yu., Sivohip J.T., Chibilev A.A. Climate dynamics and interdecadal discharge fluctuations in the Ural River basin. Doklady Earth Sciences, 2016, vol. 469 , no. 1, pp. 710-715. doi: 10.1134/ S1028334X16070096

14. Vasil'ev D.Yu., Ferapontov Yu.I. Trends in the fluctuations of near surface air temperature (a case study of Bashkiria). Izv. Akad. Nauk, Ser. Geogr., 2015, no. 1, pp. 77-86. (In Russ.).

15. Vasil'ev D.Yu., Vodopyanov V.V., Zayzeva G.S., Zakirzanov Sh.I., Semenov V.A., Sivohip J.T., Chibilev A.A. A long-term forecast model of spring runoff: the case study of the Belaya River. Doklady Earth Sciences, 2019, vol. 486, no. 6, pp. 723-726. doi: 10.1134/ S1028334X19060345

16. Vodnye resursy Rossii i ikh ispol'zovanie [Water Resources of Russia and their Use], Shiklomanov I.A., Ed. St. Petersburg: GGI Publ., 2008. 600 p.

17. Gelfand I.M., Fomin S.V. Variatsionnoe ischislenie [Variational Calculus]. Moscow: Fizmatlit Publ., 1961. $228 \mathrm{p}$.

18. Dobrovolsky S.G. The problem of global warming and changes in the flow of the Russian rivers. Water Resources, 2007, vol. 34, no. 6, pp. 643-655.

19. Dolgov S.V., Koronkevich N.I. Peculiarites of the Russian plail reivers response to the air temperature change. Izv. Akad. Nauk, Ser. Geogr., 2012, no. 6, pp. 55-62. (In Russ.).

20. Kartvelishvili N.A. Stokhasticheskaya gidrologiya [Stochastic Hydrology]. Leningrad: Gidrometeoizdat, 1975. $162 \mathrm{p}$.

21. Koronkevich N.I., Barabanova E.A., Zaytseva I.S. The effect of changes in the annual values of air temperature and precipitation on the flow of the rivers of the Russian Plain. Izv. Akad. Nauk, Ser. Geogr., 2007, no. 5, pp. 64-70. (In Russ.). 
22. Myakisheva NV, Goyuy Ch. Rhythmic annual cyclicality of hydrological processes in areas with intensive economic activity. Vestn. St.Petersburg Univ. Ser. 7, 2011, vol. 1, pp. 98-106.

23. Myakisheva N.V., Trapeznikov Yu.A. Avtoregressionnaya model' mezhgodovoi izmenchivosti gidrometeorologicheskikh protsessov [Autoregressive Model of Interannual Variability of Hydrometeorological Processes], Probabilistic analysis and modeling of oceanological processes. Leningrad: Gidrometeoizdat, 1984, pp. 31-39.

24. Muzylev S.V., Privalsky V.E. Stokhasticheskie modeli v inzhenernoi gidrologii [Stochastic Models in Engineering Hydrology]. Moscow: Nauka Publ., 1982. 184 p.

25. Ratkovich D.Ya. Mnogoletnie kolebaniya rechnogo stoka: zakonomernosti i regulirovanie [Perennial Fluctuations in River Flow: Patterns and Regulation]. Leningrad: Gidrometeoizdat, 1976. 255 p.

26. Ratkovich D.Ya., Bolgov M.V. Stokhasticheskie modeli kolebanii sostavlyayushchikh vodnogo balansa rechnogo basseina [Stochastic Models of Oscillations of the Components of the Water Balance of a River Basin]. Moscow: IWP RAS Publ., 1997. 261 p.

27. Rozhkov V.A. Teoriya $i$ metody statisticheskogo otsenivaniya veroyatnostnykh kharakteristik sluchainykh velichin $i$ funktsii [Theory and Methods of Statistical Estimation of Probability Characteristics of Random Variables and Functions]. St. Petersburg: Gidrometeoizdat, 2001. 340 p.

28. Rumyantsev V.A., Trapeznikov Yu.A. Stokhasticheskie modeli gidrologicheskikh protsessov [Stochastic Models of Hydrological Processes]. St. Petersburg: Gidrometeoizdat, 2008. 152 p.

29. Svanidze G.G. Matematicheskoe modelirovanie gidrologicheskikh ryadov [Mathematical Modeling of Hydrological Series]. Leningrad: Gidrometeoizdat, 1977. 293 p.

30. Certificate of state registration of computer programs 2018661796. Russian Federation. Realization of the method of the periodically correlated cyclostationary processes, case study of the river. Vasil'ev D.Yu., Vodopyanov V.V., Zakirzyanov Sh.N.; copyright holder: Ufa State Aviation Technical University - № 20186188838; declare 08.17.2018; registered 09.18.2018.

31. Chibilev A.A. Reka Ural [Ural River]. Leningrad: Gidrometeoizdat, 1987. 168 p.

32. Hao Z., Singh V.P. Entropy-copula method for singlesite monthly streamflow simulation. Water Resour., 2012, vol. 48. W06604. doi:10.1029/2011WR011419

33. Ricker Dennis W. Echo Signal Processing. Springer. 2003. $240 \mathrm{p}$.

34. Salvadori G., Michele C.D. Multivariate multiparameter extreme value models and return periods: a copula approach. Water Resour., 2010, vol. 46. W10501. doi:10.1029/2009WR009040

35. Torrence C., Campo G.P. A practical guide to wavelet analysis. Bull. Amer. Meteor. Soc. 1998, vol. 79, pp. 61-78.

36. Wen X., Tang G., Wang S., Hnang J. Comparison of global mean temperature series. Advances in Climate Change Research, 2011, vol. 2, no. 4, pp. 187-192. 